\title{
Assessment of Adiposity in Neurofibromatosis Type 1: Comparison between Dual Energy X-ray Absorptiometry and Conventional Methods
} Marcio L.R. Souza*, Ann K. Jansen, Luiz O.C. Rodrigues, Darlene L.S. Vilela, Adriana M. Kakehasi, Aline S. Martins, Juliana F. Souza, Nilton A. Rezende

Federal University of Minas Gerais, Belo Horizonte - MG, Brazil

Article Info

\section{Article Notes}

Received: May 22, 2020

Accepted: June 19, 2020

\section{*Correspondence:}

Souza MLR, PhD, Rua dos Guajajaras, 1470 / 1702, Belo

Horizonte, MG, Brazil

Email: marcionutricionista@yahoo.com.br.

${ }^{9} 2020$ Souza MLR. This article is distributed under the terms of the Creative Commons Attribution 4.0 International License.

\section{Keywords}

Neurofibromatosis type 1

Adiposity

Dual energy X-ray absorptiometry

Bioelectrical impedance

Skinfold thickness, Body composition

\section{Abstract}

Neurofibromatosis type 1 (NF1) is a genetic disease, characterized by multiple neural tumors as well as cutaneous symptoms. A simpler, non-invasive and cost-effective method for measuring adiposity would be useful in the care of individuals with NF1. Dual energy X-ray absorptiometry (DXA) is the standard method for this assessment but it is not widely accessible in daily clinical practice. This study aimed to compare body compositions measured using bioelectrical impedance analysis (BIA) and skinfold thickness (ST) predictive equations to those measured with DXA in twenty-six individuals with NF1. Body fat percentage (BF\%) was predicted using DXA, five ST-equations and four BIA-equations. The BF\% measured by DXA was $26.6 \pm 7.3$ and $37.4 \pm 7.2 \%$ for men and women, respectively. The best predictor of BF\% was the Sun et al. BIA equation with a smaller difference compared to DXA ( $P=0.664)$, better median of adequacy (101.0\%) and accuracy of $46.2 \%$. For males, the Kyle et al. and Lohman BIA equations were the best predictors (accuracy: 78.6 and $64.3 \%$, respectively). For females, all nine equations showed lower differences compared to DXA ( $P<0.001$ for all equations). Among ST equations, Durnin and Womersley showed a smaller difference, greater median of adequacy and percentage of adequacy compared to DXA, even when stratified by sex. This study showed that BIA equations present better adequacy and accuracy compared to SK equations. Nevertheless, these equations should be used with caution in this population due to the variations observed in comparison to DXA.

\section{Introduction}

Neurofibromatosis type 1 (NF1) is a genetic disease caused by inherited or de novo mutations on chromosome 17 , resulting in reduced neurofibromin synthesis ${ }^{\mathbf{1}}$. The most common clinical features of NF1 include café au lait spots, axillary and/or inguinal freckling, dermal and/or plexiform neurofibromas, Lisch nodules, and bone dysplasia. NF1 can also involve the endocrine, cardiovascular, musculoskeletal, and other systems $\mathbf{1}^{\mathbf{1 , 2 , 3}}$.

Assessing an individual's nutritional status is an important strategy that reflects the degree to which physiological nutrient requirements are met ${ }^{4}$. An increase in body fat at any stage of life is directly related to an increased risk of type 2 diabetes, high blood pressure, dyslipidemia, and atherosclerosis ${ }^{5}$. The distribution of adipose tissue is of great importance with regards to these comorbidities. For example, insulin resistance often occurs when fat accumulates in intra-abdominal depots and is associated with numerous cardiovascular risk factors ${ }^{6}$.

With the limitation of anthropometric indicators, such as body weight or body mass index (BMI), in predicting the distribution of body fat, assessing fat distribution in the body has gained even 
greater clinical relevance. Accurate body composition measurementsare importantto the understanding of human energy metabolism under different clinical conditions for the development of therapeutic interventions ${ }^{7}$.

Dual energy X-ray absorptiometry (DXA) is considered the gold standard for body and bone composition. DXA is based on the molecular level with three compartment measures: fat mass (FM), lean body mass (LBM) and bone mineral content (BMC). This technique evaluates these parameters regionally or in the total body, while simultaneously assessing the bone mineral density (BMD) ${ }^{8}$. DXA is an accurate, reproducible, and fast method, with a high but not excessive cost and a very low radiation dose to participants ${ }^{\mathbf{9} 10}$.

There is a great demand in the clinical practice for simpler, more practical, and cheaper methods of determining body fat, such as bioelectrical impedance analysis (BIA) or skinfolds thickness (ST). BIA is a fast, non-invasive, and relatively low-cost method compared to DXA. The analysis is based on the conduction of an electric current of low intensity with either a fixed or multiple frequencies depending on the characteristics of the equipment ${ }^{7,11}$. Different tissues in the body have different oppositions to the passage of electrical currents. This opposition, called impedance, has two vectors called resistance and reactance ${ }^{12}$.

Among the most common methods of estimating body fat and defining the body composition of individuals, the ST method has been widely used as it is simple, non-invasive with a low cost. The thickness of the skinfold reflects the thickness of the subcutaneous adipose tissue and the skin, and is used in predictive equations to calculate body density ${ }^{13}$.

Few studies ${ }^{\mathbf{1 4 , 1 5}}$ have evaluated body composition in individuals with NF1 and most of them only performed anthropometric assessment of weight, height, BMI, and head circumference. They often combined children and adults together in the analyses ${ }^{2,16-18}$. Furthermore, most studies in adults with NF1 only used DXA to assess bone characteristics but not body composition markers such as $\mathrm{LBM}$ or body fat percentage $(\mathrm{BF} \%)$.

Therefore, a controlled analysis of body composition in individuals with NF1 may be important, since previous studies have used different methods and shown inconsistent results. In addition, identifying a simpler method that better suits NF1 patients can facilitate daily clinical practice.

\section{Methods}

\section{Participant Characteristics}

This cross-sectional study included individuals with NF1 aged $\geq 18$ years from a Brazilian Neurofibromatosis Outpatient Reference Center. They were assessed between March 2016 and July 2016, and sample calculations were performed as proposed in Souza et al. ${ }^{19}$. This study was approved by the Ethics Committee of the Federal University of Minas Gerais (\#776.524-CAAE: 03005812.6.0000.5149). All patients provided their written informed consent. Patients were excluded based on musculoskeletal limitations, the use of medications that might compromise the nutritional assessment, the presence of diseases that required a specific diet or food consumption, malignant lesions, hypothyroidism, or weight loss $>10 \%$ in the last six months. Males over 50 years old and postmenopausal females with possible diagnosis of osteoporosis based on the DXA assessment were also excluded.

\section{Data Collection}

The anthropometric measurements followed the protocol provided by the World Health Organization (WHO $)^{20,21}$. Weight and height were used to calculate BMI, based on which participants were categorized into normal weight (BMI 18.5-24.9 kg/m²), underweight (BMI <18.5 $\left.\mathrm{kg} / \mathrm{m}^{2}\right)$, and overweight $\left(\mathrm{BMI} \geq 25.0 \mathrm{~kg} / \mathrm{m}^{2}\right)^{20,21}$.

The body composition was measured by DXA using the Discovery W Hologic ${ }^{\circledR}$ system (software version 3.3.0, Bedford, MA, USA) per manufacturer's instructions. The entire body was scanned for 6 minutes. Physical activity levels were evaluated using the short version of the validated International Physical Activity Questionnaire (IPAQ) ${ }^{22}$.

BIA was performed using the Quantum II ${ }^{\circledR}$ single frequency $50 \mathrm{kHz}$ tetrapolar device (RJL Systems, Clinton Township, MI, USA) per manufacturer instructions. All tests were carried out in the afternoon. Individuals were lying supine with no contact with metal objects. All participants were measured on the right side. The room temperature was controlled, and all participants were fasted with no food or liquids for at least 6 hours. The participants were also asked to refrain from physical activity 24 hours before the test. All procedures for data collection followed the protocols proposed by Kyle et al. $^{23,24}$. The resistance and reactance provided by BIA device were used to calculate the fat-free mass using four equations developed for adult individuals: Kyle et al. $^{25}$, Lohman ${ }^{26}$, Sun et al. ${ }^{27}$ and Heitmann ${ }^{28}$. The BF\% was calculated based on the fat-free mass and compared to the values obtained by DXA.

For skinfold measurements, all participants were also measured on the right side. The points to be measured were marked with a dermographic pen. The skinfolds were clamped between the thumb and index fingers and measured using a Lange $₫$ compass. The measurements were conducted in three rounds and all skinfold sites were measured before the start of the next round. Each individual was standing during measurement with the head on the Frankfurt plane, the arms relaxed at the side of the body, and the palms facing the thighs ${ }^{29}$. Nine skinfolds were evaluated: bicipital, tricipital, subscapular, suprailiac, abdominal, 
thigh, calf, middle axillary, and thoracic, according to the Lohman, Roche and Martorell standardization ${ }^{30}$. From these measured ST, the body density was calculated using the five predictive equations: Jackson and Pollock ${ }^{31}$ for men using 3 and 7 ST; Jackson, Ward and Pollock ${ }^{32}$ for women, using 3 or 7 ST; Guedes ${ }^{33}$; Petroski ${ }^{34}$; and Durnin and Womersley ${ }^{35}$. The Siri Equation ${ }^{36}$ was used to calculate the $\mathrm{BF} \%$ from the body density.

The BF\% calculated from these predictive equations were compared to that provided by DXA. The differences between these measurements and DXA as well as the adequacy and accuracy of these assessments were analyzed. Data with a maximum variation of $10 \%$ (between 90 and 110\% adequacy) were considered accurate, and those not in this range of accuracy were classified as either underestimated $(<90 \%)$ or overestimated $(>110 \%)$.

\section{Statistical Analyses}

All statistical analyses were conducted using the Statistical Package for Social Sciences $\left(\right.$ SPSS $^{\circledR}$, software version 19.0 for Windows, SPSS Inc., Chicago, IL, USA). The Kolmogorov-Smirnov test was used to evaluate normality and to determine the appropriate statistical test. Categorical variables were described using the absolute and relative (percentage) frequencies. Continuous variables with normal distribution were expressed as means and standard deviations, and compared using the paired student's $t$-test. Quantitative variables not normally distributed were presented as medians and interquartile ranges (IQR), or minimum and maximum, and compared using the nonparametric Wilcoxon test. The Bland and Altman method was used to verify the concordance between the values predicted by the equations and those by DXA. Values with $P$ $<0.05$ were considered statistically significant.

\section{Results}

Twenty-six patients aged $18-45$ years (46.2\% females) were included in this study. The mean age was $34.3 \pm$ 6.0 years with no difference between males and females $(P=0.980)$. Anthropometric and body composition data are shown in Table 1 . Based on BMI, 3 of the 26 patients $(11.5 \%)$ were classified as underweight, 16 (61.5\%) were normal weight, and 7 (27\%) were overweight.

Table 2 shows the BF\% assessed by DXA, BIA, and ST

Table 1. Demographic and anthropometric data of the sample

\begin{tabular}{|l|c|c|c|c|}
\hline \multicolumn{1}{|c|}{ Parameters } & All Patients (n=26) & $\begin{array}{c}\text { Male } \\
\text { (n=14) }\end{array}$ & $\begin{array}{c}\text { Female } \\
\text { (n=12) }\end{array}$ & Mean (SD) \\
\cline { 1 - 4 } & Mean (SD) & Mean (SD) & $32.92(6.39)$ & 0.287 \\
\hline Age (years) & $34.31(6.05)$ & $35.50(5.71)$ & $53.37(12.37)$ & 0.008 \\
\hline Weight (kg) & $62.54(16.99)$ & $70.40(16.78)$ & $1.54(0.06)$ & $<0.001$ \\
\hline Height (m) & $1.61(0.10)$ & $1.67(0.07)$ & $22.57(4.61)$ & 0.207 \\
\hline BMI (kg/m) & $23.88(4.83)$ & $24.99(4.89)$ & $37.38(7.21)$ & 0.001 \\
\hline Body fat percentage (\%) & $31.59(8.97)$ & $26.63(7.28)$ & $20.53(8.30)$ & 0.789 \\
\hline Fat mass (kg) & $20.02(8.74)$ & $19.58(9.39)$ & $31.11(5.02)$ & $<0.001$ \\
\hline Muscle mass (kg) & $40.49(11.10)$ & $48.53(8.06)$ & $1.73(0.36)$ & 0.001 \\
\hline Bone mass (kg) & $2.03(0.47)$ & $2.28(0.39)$ & \\
\hline
\end{tabular}

Note: SD: standard deviation; BMI: body mass index; kg: kilogram; m: meter; M: male; F: female; *Means were compared using paired student's $t$-test.

Table 2. Body fat percentage by sex comparing dual energy $x$-ray absorptiometry and predictive equations for bioelectrical impedance analysis and skinfold thickness

\begin{tabular}{|c|c|c|c|c|c|c|c|c|}
\hline \multirow{2}{*}{ Method } & & \multicolumn{2}{|c|}{ All $(n=26)$} & \multicolumn{2}{|c|}{ Male $(n=14)$} & \multicolumn{2}{|c|}{ Female $(n=12)$} & \multirow[t]{2}{*}{$p$-value } \\
\hline & & Media (SD) & $p$-value* & Media (SD) & $p$-value* & Media (SD) & $p$-value* & \\
\hline Dual energy $x$-ray absorptiometry & DXA & $31.59(8.97)$ & - & $26.63(7.28)$ & - & $37.38(7.21)$ & - & 0.001 \\
\hline Durnin and Womersley $(1974)^{35}$ & ST & $26.41(7.36)$ & $<0.001$ & $22.74(6.77)$ & $<0.001$ & $30.69(5.64)$ & $<0.001$ & 0.004 \\
\hline Jackson and Pollock (1978 e 1980) 31,32 skinfolds & $\mathrm{ST}^{\mathrm{a}}$ & $20.03(7.97)$ & $<0.001$ & $16.47(7.85)$ & $<0.001$ & $24.18(6.05)$ & $<0.001$ & 0.011 \\
\hline Jackson and Pollock (1978 e 1980) ${ }^{31,32} 7$ skinfolds & $\mathrm{ST}^{\mathrm{a}}$ & $21.01(8.30)$ & $<0.001$ & $17.76(8.16)$ & $<0.001$ & $24.80(6.98)$ & $<0.001$ & 0.028 \\
\hline Guedes $(1985)^{33}$ & ST & $21.12(6.55)$ & $<0.001$ & $18.44(6.72)$ & $<0.001$ & $24.26(4.91)$ & $<0.001$ & 0.021 \\
\hline Petroski $(1995)^{34}$ & ST & $23.72(7.20)$ & $<0.001$ & $21.57(7.56)$ & $<0.001$ & $26.23(6.14)$ & $<0.001$ & 0.101 \\
\hline Kyle et al. $(2001)^{25}$ & BIA & $29.83(8.83)$ & 0.005 & $25.92(8.63)$ & 0.386 & $34.40(6.85)$ & $<0.001$ & 0.011 \\
\hline Lohman $(1992)^{26}$ & BIA & $29.05(9.02)$ & 0.021 & $27.81(9.08)$ & 0.180 & $30.49(9.12)$ & $<0.001$ & 0.462 \\
\hline Sun et al. $(2003)^{27}$ & BIA & $31.27(8.05)$ & 0.664 & $28.93(7.51)$ & 0.003 & $34.00(8.09)$ & $<0.001$ & 0.110 \\
\hline Heitmann $(1990)^{28}$ & $\mathrm{BIA}$ & $26.14(9.14)$ & $<0.001$ & $23.88(9.26)$ & 0.013 & 28.77 (8.64) & $<0.001$ & 0.179 \\
\hline
\end{tabular}

Note: SD: standard deviation; DXA: dual energy x-ray absorptiometry; BIA: bioelectrical impedance analysis; ST: skinfold thickness; a: Jackson and Pollock 1978 for men and Jackson, Pollock and Ward 1980 for women; *significance between DXA and equations; "significance between men and women; Means were compared using paired Student's t-test. 
Table 3. Adequacy between body fat percentage measured by DXA and predicted by equations

\begin{tabular}{|c|c|c|c|c|c|c|c|c|}
\hline \multirow{3}{*}{ Method } & & \multicolumn{5}{|c|}{ Adequacy of Predicted Resting Metabolic Rate } & \multicolumn{2}{|c|}{$\begin{array}{c}\text { Accuracy by sex }(90-110 \%) \\
\%(n)\end{array}$} \\
\hline & & Underestimated & Accurated & Overestimated & Median & \multirow{2}{*}{ Cl95\% } & \multirow{2}{*}{ Male } & \multirow{2}{*}{ Female } \\
\hline & & $<90 \%$ & $90-110 \%$ & $>110 \%$ & (\%) & & & \\
\hline Durnin and Womersley $(1974)^{35}$ & ST & $76.9(n=20)$ & $23.1(n=6)$ & 0 & 84.02 & $80.06-87.76$ & $35.7(n=5)$ & $8.3(n=1)$ \\
\hline Jackson and Pollock (1978 e 1980) 3 skinfolds & ST & $100.0(n=26)$ & 0 & 0 & 61.80 & $55.87-66.31$ & 0 & 0 \\
\hline Jackson and Pollock (1978 e 1980) ${ }^{31,32} 7$ skinfolds & ST & $100.0(n=26)$ & 0 & 0 & 64.61 & $59.23-69.37$ & 0 & 0 \\
\hline Petroski $(1995)^{34}$ & ST & $92.3(n=24)$ & $7.7(n=2)$ & 0 & 75.18 & $70.83-79.27$ & $14.3(n=2)$ & 0 \\
\hline Kyle et al. $(2001)^{25}$ & BIA & $34.6(n=9)$ & $57.7(n=15)$ & $7.7(n=2)$ & 94.34 & $90.07-98.44$ & $64.3(n=9)$ & $50.0(n=6)$ \\
\hline Lohman $(1992)^{26}$ & BIA & $38.5(n=10)$ & $50.0(n=13)$ & $11.5(n=3)$ & 95.75 & $86.47-99.17$ & $78.6(n=11)$ & $16.7(n=2)$ \\
\hline Sun et al. $(2003)^{27}$ & BIA & $30.8(n=8)$ & $46.2(n=12)$ & $23.1(n=6)$ & 100.96 & $95.29-106.49$ & $50.0(n=7)$ & $41.7(n=5)$ \\
\hline Heitmann $(1990)^{28}$ & BIA & $65.4(n=17)$ & $34.6(n=9)$ & 0 & 82.79 & $76.07-88.06$ & $57.1(n=8)$ & $8.3(n=1)$ \\
\hline
\end{tabular}

Note: C195\%: 95\% confidence interval.

predictive equations for all individuals and stratified by sex. Among all participants, only the BIA equation of Sun et al. $^{27}$ did not underestimate the BF\% $(P=0.664)$, with the smallest difference from the values assessed by DXA at [median -0.30 ; CI95\% $(-1.20,1.85)]$. For males, the BIA equations of Kyle et al. ${ }^{25}$ and Lohman ${ }^{26}$ were better predictors of $\mathrm{BF} \%(P=0.386$ and $P=0.180$, respectively) whereas for females, all four BIA equations and all five ST equations underestimated $\mathrm{BF} \%(\mathrm{P}<0.001)$.

Table 3 shows the adequacy between the BF\% assessed by DXA and the nine predictive equations. The BIA equation of Sun et al. ${ }^{27}$ presented the greatest median of adequacy (101\%) and good accuracy at $46.2 \%$ among individuals with NF1. The ST equations showed the worst accuracy and the highest differences when compared to the DXA values for all individuals with NF1 and when stratified by sex. The Bland and Altman's plots are presented for ST equations (Figure 1) and BIA equations (Figure 2).

\section{Discussion}

NF1 is a rare genetic disease, and the scientific community seeks alternatives to improve the quality of life in these individuals. A better understanding of the body composition of individuals with NF1 enables the establishment of personalized nutritional and multidisciplinary strategies to mitigate the impacts of fat accumulation on the body. Both ST and BIA have been previously compared to DXA but not specifically in patients with NF1 ${ }^{37-42}$. In our study, the main objective was to seek accessible and practical methods for assessing body composition in individuals with NF1 to facilitate ambulatory patient care and contribute to the understanding of the body composition characteristics in patients with NF1.

In comparison to DXA, all five ST predictive equations underestimated $\mathrm{BF} \%$ in all participants and when stratified by sex. Among these equations, the Durnin and Womersley $^{35}$ equation presents the smallest difference compared to DXA, along with better accuracy and better adequacy both in males and females, although its values still deviate from those obtained by the gold standard method DXA.

All four BIA equations underestimated BF\% in women with NF1, with the equation of Kyle et al. ${ }^{25}$ showing the smallest difference compared to DXA. Among men with NF1, the best BIA equations to assess BF\% in NF1 were Kyle etal. ${ }^{25}$ and Lohmam $^{26}$.

As previously discussed, few studies ${ }^{14,15}$ have evaluated body composition in individuals with NF1, which makes comparing our findings to the existing literature difficult. No studies were found using BIA in individuals with NF1. For the ST method, Souza et al. ${ }^{15}$ used the Durnin and Womersley equation showed an average BF\% of $24.53 \%$, $19.51 \%$, and $29.23 \%$ for all NF1 patients and the subgroups of males and females, respectively. These percentages are similar to the absolute values obtained by the same method in our study. Souza et al. ${ }^{15}$ also demonstrated that the BF\% in the upper-arm muscle area was considered low in $43.3 \%$ of the volunteers and the BF\% was classified as high in $30 \%$ of the sample.

Another study ${ }^{\mathbf{1 4}}$ used quantitative peripheral computed tomography to compare the bones and skeletal muscles of 40 children with NF1 to those in 380 volunteers aged between 5 and 18 years and not affected by this disease. This study demonstrated that children with NF1 had smaller muscle cross-sectional areas than their controls, with no further details regarding the pathophysiology of this finding. Notably, it is a study carried out in children, which makes it difficult to compare it to research conducted in adults ${ }^{14}$. There has been no studies so far using DXA to assess lean mass or BF\% in adults with NF1, and most studies using DXA have only assessed bone characteristics, without detailing of body composition.

The application of BF\% predictive equations by ST and BIA needs to be carried out with caution in NF1, since most of these equations underestimate $\mathrm{BF} \%$ in this population. In addition, these equations were developed in different populations and it is therefore interesting to evaluate their accuracy in comparison to $\mathrm{DXA}^{43}$. 

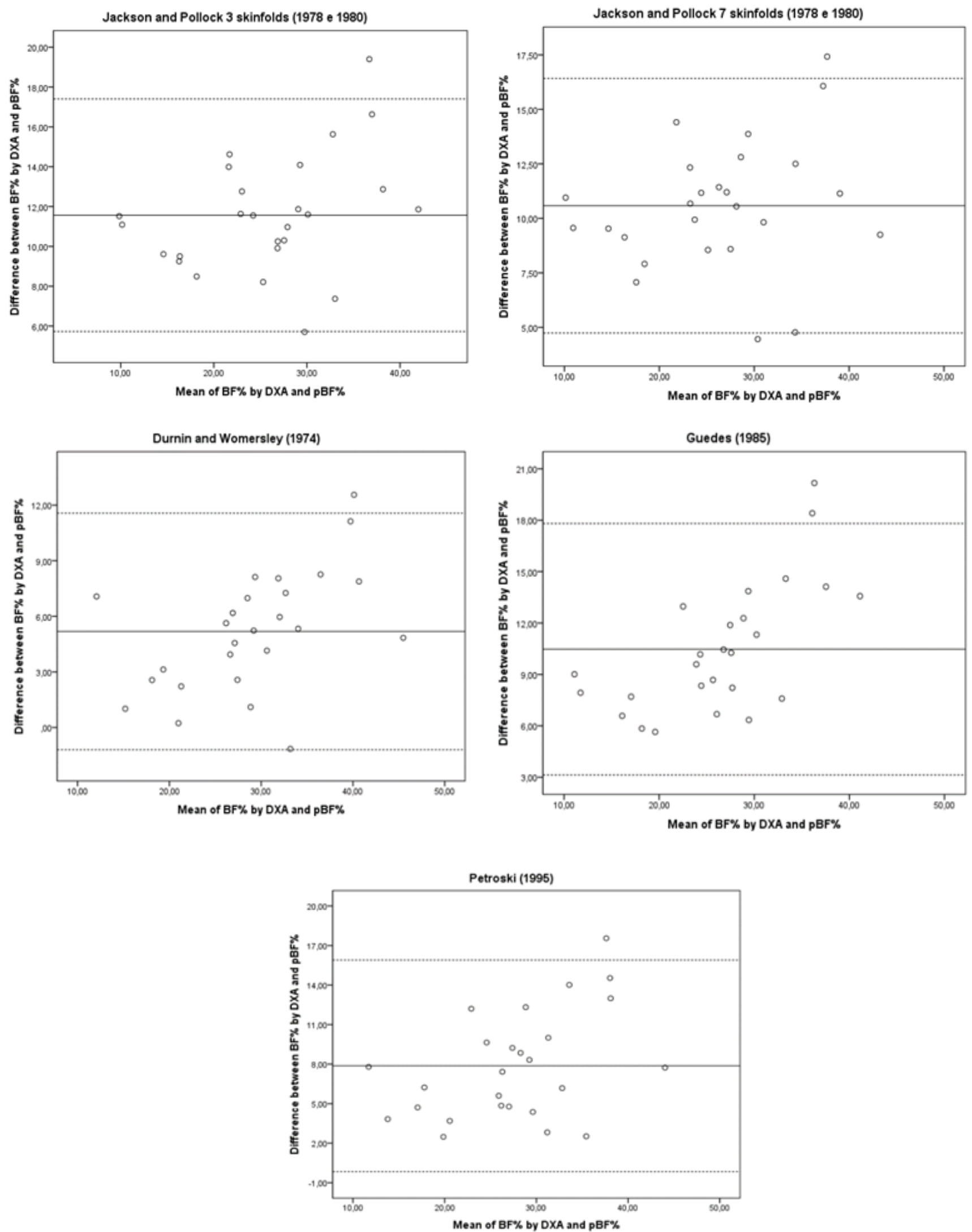

Note: BF\% by DXA: body fat percentage by DXA; pBF\%: predicted body fat percentage

Figure 1: Bland and Altmam plots for DXA and skinfold thickness comparisons. 

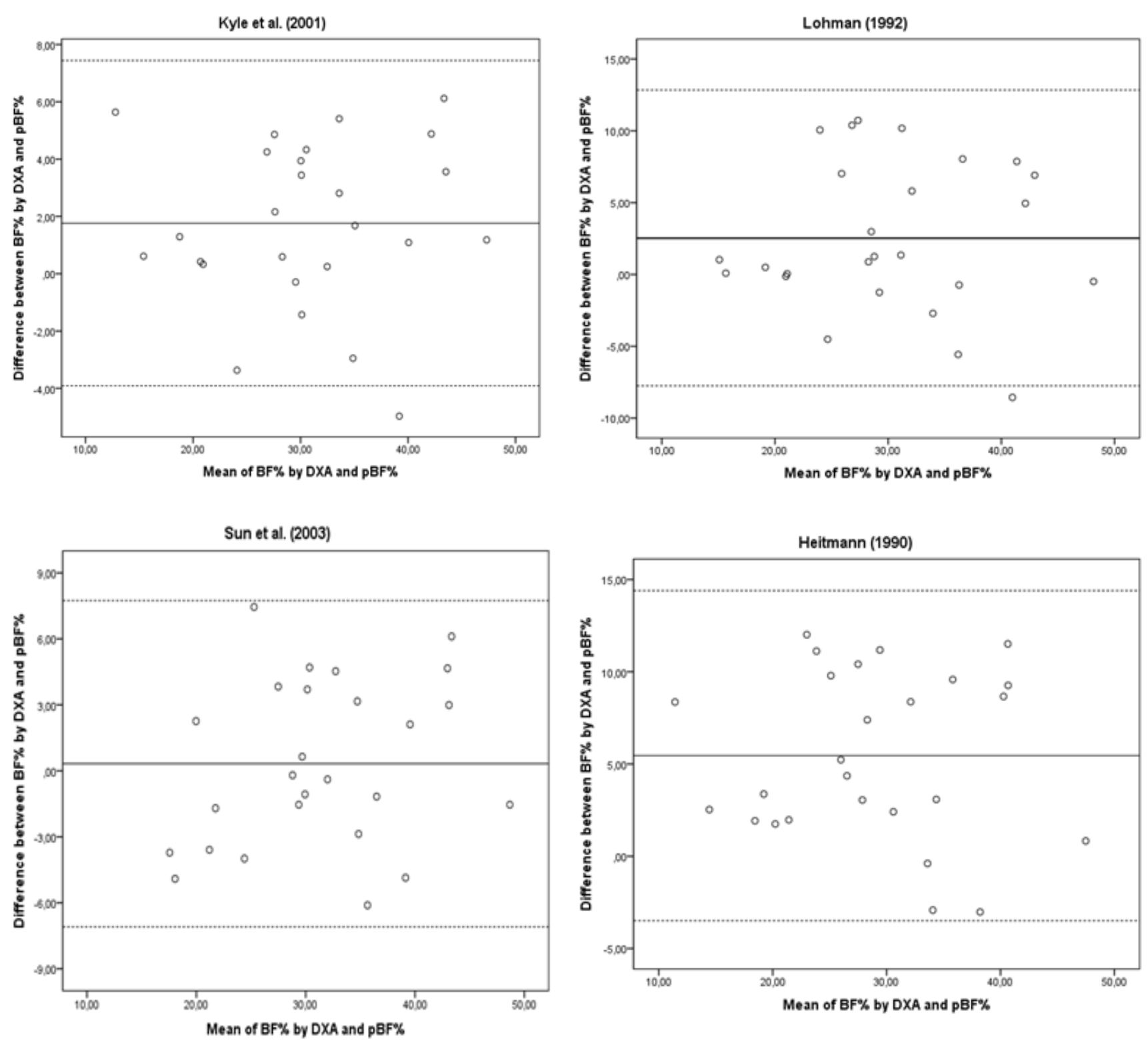

Note: BF\% by DXA: body fat percentage by DXA; pBF\%: predicted body fat percentage

Figure 2: Bland and Altmam plots for DXA and bioelectrical impedance comparisons.

In this study, all predictive equations did not perform well when compared to DXA, which is considered the gold standard for assessing body composition; however, the BIA equations showed smaller deviations from DXA than the ST equations among NF1 patients. Validation studies or proposition of new predictive equations for NF1 patients are warranted in future studies. Randomization would be important in improving the external validity of similar studies. Despite these limitations, this study is clinically important in exploring simpler methods to assess body composition in the care of individuals with NF1. These patients suffer from the uncertainty of disease progression and a lack of cure for the growth of neurofibromas ${ }^{44}$, and a better understanding of their nutritional characteristics and body composition may help improve quality of life in patients of NF1.

\section{Conclusions}

This study demonstrates that BIA equations present better adequacy and accuracy than SK equations in individuals with NF1, using DXA as the reference method. Nevertheless, these equations should be used with caution in this population due to the deviations observed in comparison to DXA. The body composition of patients with NF1 needs to be better studied in the future to determine the possible impacts on the clinical characteristics of this disease. 


\section{Financial support}

The authors received financial support from three Brazilian government funding agencies: CAPES, National Council of Technological and Scientific Development CNPq (\#471725/2013-7) and FAPEMIG (\#APQ-00928-11; \#PPM-00120-14). The funding sources played no role in the design, analysis, writing, or decision to publish.

\section{Author Contributions}

All authors (MLRS, AKJ, LORC, DLVS, AMK, ASM, JFS e NAR) conceived, planned and performed the work leading to the report and interpreted the results. Also written, reviewed and approved the final version.

\section{References}

1. Rodrigues LO, Batista PB, Goloni-Bertollo EM, etal. Neurofibromatoses: part 1 - diagnosis and differential diagnosis. Arq Neuropsiquiatr. 2014; 72(3): 241-250

2. Souza JF, Toledo LL, Ferreira MCM, et al. Neurofibromatose Tipo 1 : mais comum e mais grave do que se imagina. Rev Assoc Med Bras. 2009; 55(4): 394-9.

3. Korf BR. Neurofibromatosis. Handb Clin Neurol. 2013; 111: 333-40.

4. Hammond KA. Avaliacao Dietética e Clínica. In: Mahan LK; EscottStump S. (Ed.) Alimentos, nutricao e dietoterapia. Sao Paulo Roca. 2002; 341-366.

5. Juonala M, Magnussen CG, Berenson GS, et al. Childhood adiposity, adult adiposity, and cardiovascular risk factors. N Engl J Med. 2011; 365: 1876-85.

6. Chait A, den Hartigh LJ. Adipose tissue distribution, inflammation and its metabolic consequences, includeing diabetes and cardiovascular disease. Front Cardiovasc Med. 2020; 7: 22.

7. Guedes DP. Procedimentos clínicos utilizados para análise da composição corporal. Revista Brasileira de Cineantropometria \& Desempenho Humano. 2013; 15(1): 113-129.

8. Bazzocchi A, Ponti F, Albisinni U, et al. DXA: technical aspects and application. European Journal of Radiology. 2016; 85(8): 1481-1492.

9. Baim S, Wilson CR, Lewiecki EM, et al. Precision assessment and radiation safety for dual-energy X-ray absorptiometry: position paper of the International Society for Clinical Densitometry. J Clin Densitom. 2005; 8(4): 371-378.

10. Shepherd JA, Ng BK, Sommer MJ, et al. Body composition by DXA Bone. 2017; 104: 101-105.

11. Fosbol M0, Zerahn B. Contemporary methods of body composition measurement. Clinical physiology and functional imaging. 2015; 35(2): 81-97.

12. Eickemberg M, Oliveira CC, Roriz AK, et al. Bioimpedância elétrica e gordura visceral: uma comparação com a tomografia computadorizada em adultos e idosos. Arquivos Brasileiros de Endocrinologia \& Metabologia. 2013; 57(1): 27-32.

13. Lazzer S, Boirie Y, Meyer M, etal. Which alternative method to dual-energy $\mathrm{X}$-ray absorptiometry for assessing body composition in overweight and obese adolescents? Arch Pediatr. 2005; 12(7): 1094-101.

14. Stevenson D, Moyer-Mileur L, Carey J, et al. Case-control study of the muscular compartments and osseous strength in neurofibromatosis type 1 using peripheral quantitative computed tomography. Journal of Musculoskeletal and Neuronal Interactions. 2005; 5(2): 145-149.

15. Souza M, Jansen A, Martins A, et al. Body composition in adults with neurofibromatosis type 1. Rev Assoc Med Bras. 2016; 62(9): 831-836.
16. Szudek J, Birch P, Friedman JM. Growth in North American white children with neurofibromatosis 1 (NF1). J Med Gen. 2000; 37: 933938.

17. Trovó-Marqui AB, Goloni-Bertollo EM, Valério NI, et al. High frequencies of plexiform neurofibromas, mental retardation, learning difficulties, and scoliosis in Brazilian patients with neurofibromatosis type 1. Braz J Med Biol Res. 2005; 38(9): 1441-47.

18. Petramala L, Giustini S, Zinnamosca L, et al. Bone mineral metabolism in patients with neurofibromatosis type 1 (von Recklingausen disease). Arch Dermatol Res. 2012; 304: 325-331.

19. Souza MLR, Jansen AK, Rodrigues LOC, et al. Increased resting metabolism in neurofibromatosis type 1. Clinical Nutrition ESPEN. 2019; 32: 44-49.

20. WHO - World Health Organization. Physical status: the use and interpretation of anthropometry. Genebra. 1995; 452p. (Technical Report Series No. 854).

21. WHO - World Health Organization. Obesity - preventing and managing the global epidemic. Report of a WHO consultation on obesity. Genebra. 2000; 253p. (Technical Report Series, No.894).

22. Craig CL, Marshall AL, Sjostrom M, et al. International physical activity questionnaire: 12-country reliability and validity. Med Sci Sports Exerc. 2003; 35(8): 1381-1395.

23. Kyle UG, Bosaeus I, De Lorenzo AD, et al. Bioelectrical impedance analysis - part I: review of principles and methods. Clin Nutr. 2004; 23(5): 1226-1243.

24. Kyle UG, Bosaeus I, De Lorenzo AD, et al. Bioelectrical impedance analysis - part II: utilization in clinical practice. Clin Nutr. 2004; 23(6): 1430-1453.

25. Kyle UG, Genton L, Karsegard L, et al. Single prediction equation for bioelectrical impedance analysis in adults aged 20-94 years. Nutrition. 2001; 17(3): 248-53.

26. Lohman TG. Advances in body composition assessment: current issues in exercises science. Illinois: Human Kinetic Publisher. 1992; 160 p.

27. Sun SS, Chumlea WC, Heymsfield SB, et al. Development of bioelectrical impedance analysis prediction equations for body composition with the use of a multicomponente model for use in epidemiologic surveys. Am J Clin Nutr. 2003; 77(2): 331-340.

28. Heitmann BL. Prediction of body water and fat in adult Danes from measurement of electrical impedance. A validation study. Int J Obesity. 1990; 14(9): 789-802.

29. Heyward VH, Stolarczyl LM. Avaliacao da composicao corporal aplicada. Sao Paulo Editora Manole. 2000; 243p.

30. Lohman TG, Roche AF, Martorell R. Anthropometric standardization reference manual. Illinois Human Kinetics Books. 1988; 90p.

31. Jackson AS, Pollock ML. Generalized equations for predicting body density of men. Br J Nutr. 1978; 40(3): 497-504.

32. Jackson AS, Pollock ML, Ward A. Generalized equations for predicting body density of women. Med Sci Sports Exerc. 1980; 12(3): 175-81.

33. Guedes DP. Estudo da gordura corporal através da mensuração dos valores de densidade corporal e da espessura das dobras cutâneas em universitarios. Kinesis. 1985; 1(2): 183-212.

34. Petroski EL. Desenvolvimento e validacao de equacoes generalizadas para a estimativa da densidade corporal em adultos. Tese de Doutorado aprovada no Programa de Pos-graduacao em Ciencias do Movimento Humano, Universidade Federal de Santa Maria, Santa Maria, Rio Grande do Sul. 1995; 124 p.

35. Durnin JVGA, Womersley J. Body fat assessed from total body density and its estimation from skinfold thickness: measurements on 481 men and women aged from 16 to 72 years. Br J Nutr. 1974; 32: 77-97. 
36. Siri WE. Body composition from fluid spaces and density analysis of methods. In: Brozek J, Henschel A. Techniques for measuring body composition. Washington National Academy of Sciences. 1961.

37. King S, Wilson J, Kotsimbos T, et al. Body composition assessment in adults with cystic fibrosis: comparison of dual-energy X-ray absorptiometry with skinfolds and bioelectrical impedance analysis. Nutrition. 2005; 21(11-12): 1087-1094.

38. Chambers AJ, Parise E, McCrory JL, et al. A comparison of prediction equations for the estimation of body fat percentage in non-obese and obese older Caucasian adults in the United States. J Nutr Health Aging. 2014; 18(6): 586-590.

39. Cui Z, Truesdale KP, Cai J, et al. Evaluation of anthropometric equations to assess body fat in adults: NHANES 1999-2004. Med Sci Sports Exerc. 2014; 46(6): 1147-1158.

40. Shafer KJ, Siders WA, Johnson LK, et al. Validity of segmental multiplefrequency bioelectrical impedance analysis to estimate body composition of adults across a range of body mass indexes. Nutrition. 2009; 25(1): 25-32.

41. Oeffinger DJ, Gurka MJ, Kuperminc M, et al. Accuracy of skinfold and bioelectrical impedance assessments of body fat percentage in ambulatory individuals with cerebral palsy. Dev Med Child Neurol. 2014; 56(5): 475-481.

42. Stevens J, Truesdale KP, Cai J, et al. Nationally representative equations that include resistance and reactance for the prediction of percent body fat in Americans. Int J Obes (Lond). 2017; 41(11): 1669-1675.

43. Stevens J, Ou FS, Cai J, et al. Prediction of percent body fat measurements in Americans 8 years and older. Int J Obes (Lond). 2016; 40(4): 587-594.

44. Draucker CB, Nutakki K, Varni JW, et al. The health-related quality of life of children, adolescents, and young adults with neurofibromatosis type 1 and their families: analysis of narratives. J Spec Pediatr Nurs. 2017; 22(2): e12174. 